\title{
Cyclooxygenase enzymes and prostaglandins in pathology of the endometrium
}

\author{
Kurt J. Sales and Henry N. Jabbour* \\ MRC Human Reproductive Sciences Unit, Centre for Reproductive Biology, University of Edinburgh \\ Academic Centre, 49 Little France Crescent, Old Dalkeith Road, Edinburgh, EH16 4SB, UK
}

\begin{abstract}
Prostaglandins are bioactive lipids produced from arachidonic acid by cyclooxygenase (COX) enzymes and specific terminal prostanoid synthase enzymes. After biosynthesis, prostaglandins exert an autocrine-paracrine function by coupling to specific prostanoid $G$ protein-coupled receptors to activate intracellular signalling and gene transcription. For many years, prostaglandins have been recognized as key molecules in reproductive biology by regulating ovulation, endometrial physiology and proliferation of endometrial glands and menstruation. More recently, a role for COX enzymes and prostaglandins has been ascertained in reproductive tract pathology, including carcinomas, menorrhagia, dysmenorrhoea and endometriosis. Although the mechanism by which prostaglandins modulate these pathologies is still unclear, a large body of evidence supports a role for COX enzymes, prostaglandins and prostaglandin receptor signalling pathways in angiogenesis, apoptosis and proliferation, tissue invasion and metastases and immunosuppression. Here, an overview is provided of some of the findings from these studies with specific emphasis on the role of COX enzymes, prostaglandin $\mathrm{E}_{2}$ and $\mathrm{F}_{2 \alpha}$ in disorders of endometrial proliferation and menstruation in non-pregnant women.
\end{abstract}

The arachidonic acid cascade generates a family of bioactive lipids, including prostaglandins, thromboxanes and leukotrienes that modulate diverse physiological and pathophysiological responses in the reproductive tract. There has been a great deal of interest over the past few years in the involvement of arachidonic acid metabolites in pathology. However, there is still much uncertainty about the manner in which they contribute to specific phenotypic cellular changes that may precipitate pathophysiology. The focus of this review is to provide some insight into the role of cyclooxygenase (COX) enzymes, prostaglandin $\mathrm{E}_{2}\left(\mathrm{PGE}_{2}\right)$ and $\mathrm{PGF}_{2 \alpha}$ and their respective receptors in reproductive pathophysiology, with specific regard to disorders of endometrial proliferation and dysfunctional menstruation.

The kinetics of the prostaglandin biosynthetic pathway is driven by the availability of free arachidonic acid. When released from plasma membrane phospholipids or dietary fatty acids, after activation of phospholipase A2 (PLA2) or PLC, arachidonic acid is cyclized and oxygenated by COX enzymes by addition of the 15-hydroperoxy group to form prostaglandin $\mathrm{G}_{2}\left(\mathrm{PGG}_{2}\right)$. The hydroperoxy group of $\mathrm{PGG}_{2}$ is reduced to the hydroxy

*Correspondence

Email: h.jabbour@hrsu.mrc.ac.uk group of $\mathrm{PGH}_{2}$ (Marnett, 1992) (Fig. 1). This intermediate serves as the substrate for terminal prostanoid synthase enzymes. These enzymes are named according to the prostaglandin they produce, such that prostaglandin $\mathrm{D}_{2}$ is synthesized by prostaglandin-D-synthase (PGDS), prostaglandin $\mathrm{E}_{2}\left(\mathrm{PGE}_{2}\right)$ by prostaglandin-E-synthase (PGES); prostaglandin $\mathrm{F}_{2 \alpha}$ by prostaglandin-F-synthase (PGFS), prostacyclin by prostaglandin-I-synthase (PGIS) and thromboxane by thromboxane synthase (TXS) (Narumiya et al., 1999) (Fig. 1). The physiological response to oxygenation of arachidonic acid is determined by the expression of terminal synthase enzymes in specific cells and tissues, as each prostaglandin has its own range of biological activities that may be cell-type specific.

Three isoforms of COX enzyme (COX-1, COX-2 and COX-3) catalyse the commited step in prostanoid biosynthesis (Chandrasekharan et al., 2002; Morita, 2002). The structures of COX-1 and COX-2 from various species have been well characterized and several functional roles for COX-1 and COX-2 in physiology and pathology have now been ascertained (Morita, 2002). A functional role for COX-3 in human physiology and pathophysiology remains to be established.

COX-1 is generally considered to be involved in performing normal physiological functions. However, $C O X-2$ is an immediate early gene which is rapidly 


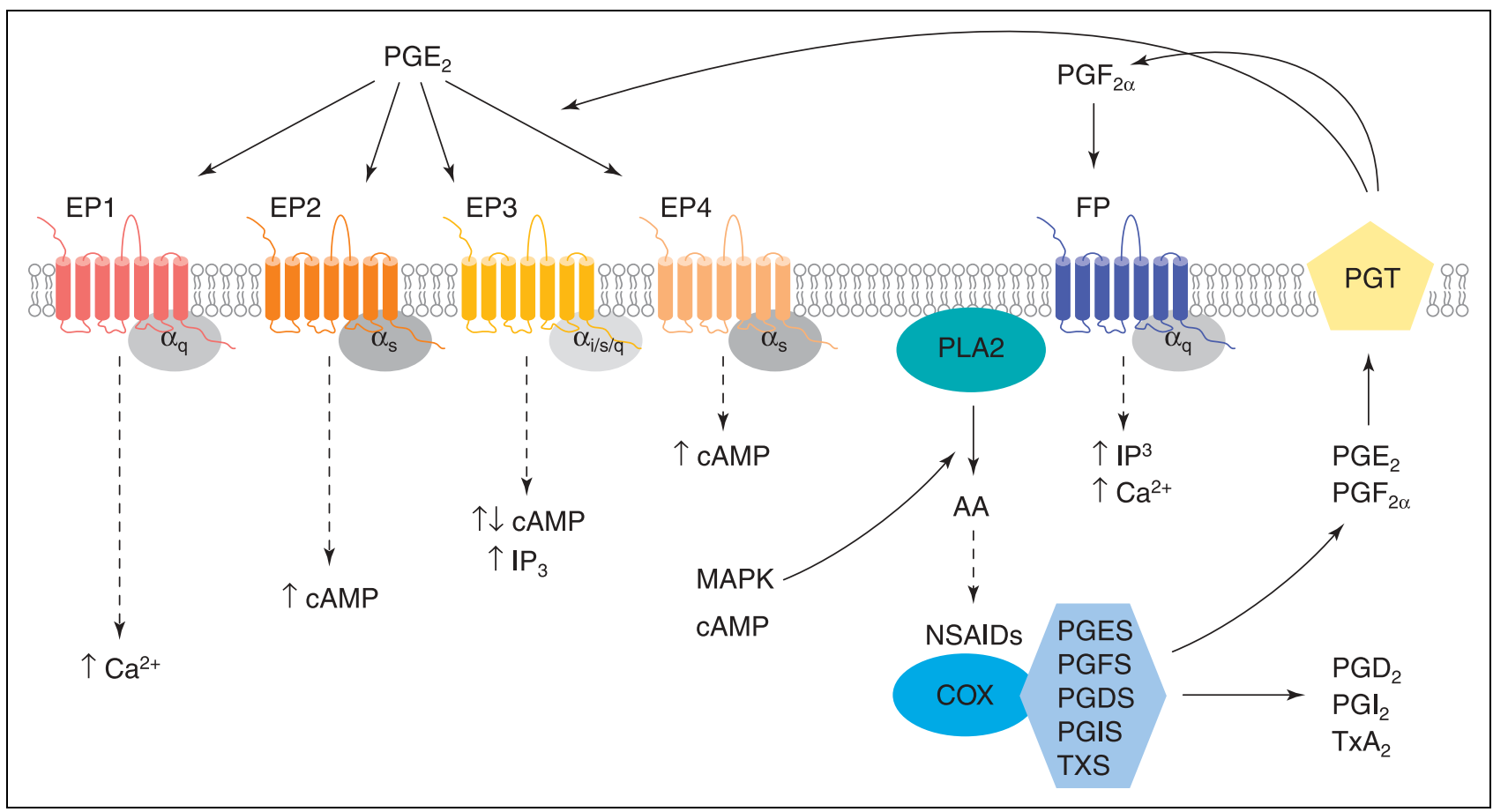

Fig. 1. Schematic representation of the cyclooxygenase-prostanoid biosynthetic and signalling pathway. Arachidonic acid (AA) is released from plasma membrane phospholipids by phospholipase A2 (PLA2) and utilized by cyclooxygenases (COX) and specific synthase enzymes to form prostaglandin (PG), $\mathrm{PGD}_{2}, \mathrm{PGE}_{2}, \mathrm{PGF}_{2 \alpha}, \mathrm{PGI}_{2}$ and thromboxane (TX) $\mathrm{A}_{2}$. These products are actively transported out of the cell by a prostanoid transporter (PGT), on which they exert an autocrine-paracrine effect by coupling to heptahelical transmembrane receptors to activate intracellular signalling. Inhibitors of COX enzyme function such as non-steroidal anti-inflammatory drugs (NSAIDs) can block PG biosynthesis and subsequent downstream events. IP ${ }_{3}$ : inositol trisphosphate; MAPK: mitogen-associated protein kinase; PGDS: prostaglandin-D-synthase; PGES: prostaglandin-E-synthase; PGFS: prostaglandin-F-synthase; PGIS: prostaglandin-I-synthase; TXS: thromboxane synthase.

induced by growth factors, oncogenes, carcinogens and tumour-promoting phorbol esters, and a role for it has been ascertained in rheumatic disease, inflammation and tumorigenesis (Morita, 2002). The importance of COX-1 and COX-2 in reproduction has been observed from studies of knockout mouse model systems. COX-1-deficient mice exhibit longer gestation periods, protracted parturition and deliver fewer live young compared with wild-type mice. Conception and fetal development are unaltered in COX-1-deficient mice, indicating that prostanoids produced by COX-1 are not critical for ovulation, fertilization or implantation, but are essential for initiating labour (Langenbach et al., 1995; Gross et al., 1998). Ablation of the COX-2 gene in mice results in multiple reproductive failures, including ovulation, fertilization, implantation and decidualization confirming that prostaglandins produced by COX-2 play a crucial role in these processes (Dinchuk et al., 1995; Lim et al., 1997; Langenbach et al., 1999a,b). On the basis of these findings, it would appear that although both COX isoforms essentially catalyse the same reaction, they differ in their tissue-specific distribution in the reproductive tract so that there are clear differences in the prostanoid profile and functions. However, few data are available on the distribution of COX-1 and COX-2 in reproductive tissues, or on the distribution of the respective synthase enzymes in the reproductive tissues of the COX-1 and COX-2 knockout mice, and the extent to which these enzymes are co-regulated with the COX enzymes, as these synthase enzymes are probably the more crucial determinants of the prostanoid profile.

COX-3 shares all the structural and catalytic features of COX-1 and COX-2, but exhibits a vastly different pharmacology. COX-1 and COX-2 are inhibited by a broad spectrum of anti-inflammatory drugs. By contrast, COX-3 appears to be sensitive to drugs that are antipyreticanalgaesic and that have low anti-inflammatory properties (Chandrasekharan et al., 2002). This finding indicates that COX-3 plays a role in eicosanoid biosynthesis that is different from that of COX-1 and COX-2.

\section{Prostaglandins and their receptors}

After biosynthesis, prostanoids are transported out of the cell by a prostaglandin transporter (PGT) (Chan et al., 1998), where they exert their biological function through G-protein receptor (GPCR)-mediated interaction (Fig. 1). There are eight types and subtypes of prostanoid receptor, which are encoded by different genes. Separate receptors, showing selective ligand binding specificity, have 
been described for $\mathrm{PGD}_{2}, \mathrm{PGE}_{2}, \mathrm{PGF}_{2 \alpha}$, thromboxane $\mathrm{A}_{2}$ $\left(\mathrm{TxA}_{2}\right)$ and $\mathrm{PGI}_{2}$ (Narumiya et al., 1999). The focus of this review is mainly on the $\mathrm{E}$ and $\mathrm{F}$ series of prostaglandins in the endometrium, which exert their biological functions via $\mathrm{EP}$ and $\mathrm{FP}$ receptors respectively.

\section{$E P$ and FP receptors}

$\mathrm{PGE}_{2}$ elicits its autocrine-paracrine effects on target cells after interaction with four sub-types of $\mathrm{PGE}_{2}$ receptor (Coleman et al., 1994), which have been pharmacologically divided into EP1, EP2, EP3 and EP4. These receptors use alternate and in some cases opposing intracellular pathways (Ashby, 1998) (Fig. 1). Interaction of $\mathrm{PGE}_{2}$ with the EP1 receptor mobilizes intracellular calcium and inositol trisphosphate $\left(\mathrm{IP}_{3}\right)$ via $\mathrm{G}_{\alpha q}$ (Fig. 1). Activation of the EP2 and EP4 receptors results in an increase in cAMP accumulation via $\mathrm{G}_{\alpha \mathrm{s}}$ (Sugimoto et al., 1993; Narumiya et al., 1999). There are several splice variants for the EP3 receptor, which are coupled to different signalling pathways that result in either a positive or negative CAMP response to $\mathrm{PGE}_{2}$ administration or increase in intracellular calcium mobilization and accumulation of $\mathrm{IP}_{3}$, depending on the splice variant and type of cell (Sugimoto et al., 1993; Narumiya et al., 1999) (Fig. 1).

$\mathrm{PGF}_{2 \alpha}$ exerts its action via FP receptors and alternative mRNA splice variants designated $\mathrm{FP}_{\mathrm{A}}$ and $\mathrm{FP}_{\mathrm{B}}$ have been reported. These splice variants are identical except for their intracellular carboxyl-terminal domain, which is truncated in the $\mathrm{FP}_{\mathrm{B}}$ isoform and lacks the last 46 carboxyl-terminal amino acids (Fujino et al., 2002). Both isoforms of FP receptor are coupled to $G_{\alpha q}$ and can activate $\mathrm{IP}_{3}$ via activation of phospholipase $\mathrm{C}$, intracellular calcium flux and activation of protein kinase C. In addition, both isoforms can activate Rho, a member of the Ras family of small GTPases, which in turn leads to phosphorylation and activation of focal adhesion kinase associated with cell morphology (Narumiya et al., 1999).

In general, it has been assumed that signal transduction cascades are initiated after ligand-receptor binding at the plasma membrane. However, Bhattacharya et al. (1998, 1999) have ascertained a nuclear location for EP receptors, indicating that $\mathrm{PGE}_{2}$ directly regulates the transcription of target genes after the release of calcium from nuclear calcium pools or by activation of calcium channels. In addition, it is possible that $\mathrm{PGE}_{2}$ influences transcription of target genes by interacting with nuclear peroxisome proliferator-activated receptors (PPAR). Although no role for $\mathrm{PGE}_{2}, \mathrm{PGF}_{2 \alpha}$ and PPAR in regulation of gene transcription has been described, prostanoids such as $\mathrm{PGI}_{2}$ and $P \mathrm{PJ}_{2}$ have been reported as ligands for PPAR $\alpha$ and PPAR $\delta$, which alter transcription of target genes involved in lipid metabolism and homeostasis (Forman et al., 1997). This diversity of receptors with opposing functions may confer a homeostatic control of an autocoid, which is released in high concentrations close to its site of synthesis (Ashby, 1998).

Functional roles for the prostanoid receptors have been determined by studies in knockout mouse model systems, deficient for each of the receptors. The most startling observations arising from these studies have been derived from the EP2 and FP receptor knockouts, which have shown that the EP2 and FP receptors are indispensable in female reproduction (Hizaki et al., 1999; Kennedy et al., 1999; Tilley et al., 1999; Narumiya and FitzGerald, 2001). Loss of EP2 receptor function by gene ablation in mouse model systems results in impaired ovulation and marked reduction in litter size (Hizaki et al., 1999; Kennedy et al., 1999; Tilley et al., 1999), whereas ablation of the FP receptor in mice results in loss of parturition, although the pups can be successfully rescued by Caesarean section (Narumiya and FitzGerald, 2001). In FP null mice, there is loss of induction of the oxytocin receptor and maintenance of serum progesterone (both of which can be restored following ovariectomy). This finding reinforces the proposal for an essential role for $\mathrm{PGF}_{2 \alpha}$ in parturition and regulation of expression of the oxytocin receptor (Sugimoto et al., 1998).

\section{COX enzymes and prostaglandins in endometrial pathology}

Over the past decade, many epidemiological, pharmacological and laboratory studies using gene disruption and gene overexpression systems have provided conclusive evidence to support a role for COX enzymes and prostanoids in pathophysiology (Chulada et al., 2000). In this section, some of the functions for COX enzymes and prostaglandins in endometrial dysfunction and pathology are highlighted.

\section{Carcinomas}

Recent studies have indicated that there is a correlation between upregulated expression of COX enzymes and uterine carcinomas. Expression of COX-1 is unaltered in endometrial carcinomas (Tong et al., 2000), but is upregulated in carcinomas of the uterine cervix (Sales et al., 2002a). By contrast, COX-2 expression is upregulated in endometrial (Tong et al., 2000; Jabbour et al., 2001; Ferrandina et al., 2002) and cervical carcinomas (Ryu et al., 2000; Kulkarni et al., 2001; Sales et al., 2001) and localized in both neoplastic epithelial and endothelial cells. These findings have led to the observation that COX enzyme inhibitors may be of potential benefit as therapeutic regimens for uterinecervical carcinomas, as has been suggested for other types of carcinoma highly expressing COX enzyme (Subbaramaiah et al., 1997).

Upregulated expression of COX enzymes in uterine and cervical carcinomas coincides with an increase in 


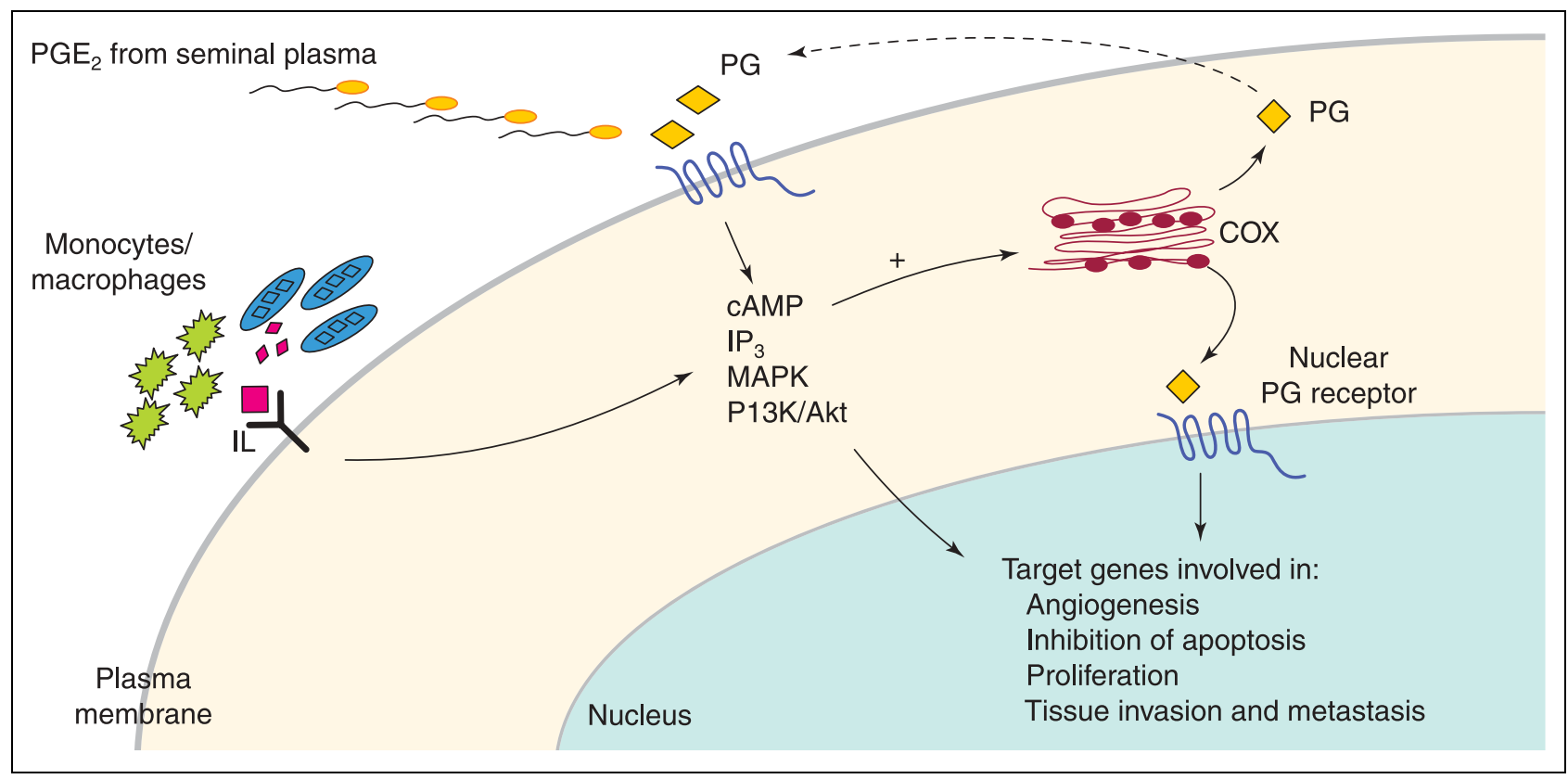

Fig. 2. Possible mechanisms involved in the autocrine-paracrine-intracrine regulation of cyclooxygenase (COX) enzyme expression in epithelial and endothelial cells. A positive feedback loop is formed by prostaglandins (PG) to promote intracellular signalling via the CAMP, inositol trisphosphate $\left(\mathrm{IP}_{3}\right)$, mitogen-associated protein kinase (MAPK) and phosphatidyl inositol 3 kinase-protein kinase B (PI3K/Akt) pathways, and induction of COX enzyme expression. This positive feedback loop, in turn, results in activation of transcription of target genes involved in angiogenesis, inhibition of apoptosis, proliferation and tissue invasion and metastasis. In addition, the COX-prostanoid biosynthetic and signalling pathway, especially in neoplastically transformed endocervical cells, may also be regulated by immune function, cytokines, chemokines and seminal plasma prostanoids.

the synthesis and secretion of $\mathrm{PGE}_{2}$, expression and signalling of EP receptors and an increase in PPAR (Ryu et al., 2000; Tong et al., 2000; Jabbour et al., 2001; Kulkarni et al., 2001; Sales et al., 2001). These findings indicate an autocrine-paracrine-intracrine regulation of neoplastic cell function by prostanoids in response to coupling with either transmembrane or nuclear EP receptors, or nuclear PPAR. A role for $\mathrm{PGE}_{2}$ and EP receptor function in tumorigenesis has been established using several in vitro and in vivo model systems (Watanabe et al., 1999, 2000; Sheng et al., 2001). Therefore, it is possible that interaction of $\mathrm{PGE}_{2}$ with target receptors in uterine and cervical carcinomas potentiates tumorigenesis by activating various signal transduction cascades and consequently transcription of target genes involved in enhancing or maintaining the neoplastic state. A model for autocrine-paracrine-intracrine regulation of neoplastic cell function is depicted schematically (Fig. 2). Although much emphasis has been placed on a role for $\mathrm{PGE}_{2}$ in regulating neoplastic cell function, other prostanoids using the same signal transduction pathways may similarly enhance or contribute towards the neoplastic state. Milne and Jabbour (2003) have demonstrated a role for $\mathrm{PGF}_{2 \alpha}$ in enhancing epithelial cell proliferation in endometrial adenocarcinoma cells and it is postulated that similar mechanisms may regulate uterine carcinomas in situ. Moreover, in sexually active women diagnosed with dysplasia, growth and invasiveness of uterine-cervical tissues may also be modulated by $\mathrm{PGE}_{2}$ present in seminal plasma (Fig. 2). Sales et al. (2002b) have demonstrated a role for seminal plasma and $\mathrm{PGE}_{2}$ in activating COX-2 and EP receptor expression and signalling in cervical adenocarcinoma cells. These findings imply that selective inhibition of COX enzyme expression is only of partial therapeutic benefit for sexually active women with cervical malignancy, as cervical tumours may be modulated additionally by prostaglandins present in seminal plasma. The extent to which the cervical mucus plug in such women prevents contact with the prostanoids present in seminal plasma is unknown, as is the proportion of the endocervical canal which will be in contact with the seminal plasma prostaglandins (Fig. 2).

\section{Menorrhagia}

Menorrhagia, with the absence of uterine pathology, is a clinical definition for dysfunctional uterine bleeding with excessive menstrual blood loss (defined as $>80 \mathrm{ml}$ of blood lost per menstrual cycle). Menorrhagia affects $10-30 \%$ of women of reproductive age and up to $50 \%$ of perimenopausal women (Haynes et al., 1977; Fraser, 1992; Prentice, 2000). Although the aetiology of aberrant menstruation, including menorrhagia, is poorly 
understood, several studies have associated heavy menstrual blood loss with abnormalities in vasodilatatory prostanoid production and secretion from the uterus (Buttram and Reiter, 1981; Smith et al., 1981a,b).

In women diagnosed with menorrhagia, $\mathrm{PGE}_{2}$ synthesis and the number of PGE binding sites are greater in uterine tissues compared with those of normal women and correlate directly with menstrual blood loss (Smith et al., 1981a; Hofmann et al., 1983; Rees et al., 1984a; Adelantado et al., 1988a,b). Synthesis of $\mathrm{PGI}_{2}$ and nitric oxide are also high in menstrual blood collected from menorrhagic endometrium of women presenting with excessive menstrual bleeding (Smith et al., 1981b; Makarainen and Ylikorkala, 1986). This finding indicates that the degree or duration of menstrual bleeding in women diagnosed with menorrhagia may be augmented after an increase in vasodilatatory factors. The increase in these vasodilatatory factors may further enhance menstrual bleeding and vascular dysfunction by upregulating the COX-PG biosynthetic pathway via a positive feedback loop, and promote an autocrine-paracrine regulation of growth factors specific for vascular function (vascular endothelial growth factors, VEGFs) (Chiarugi et al., 1998; Clancy et al., 2000). Prostaglandins are known to increase COX enzyme expression, arachidonic acid metabolism and prostanoid biosynthesis in several model systems (Maldve et al., 2000; Sales et al., 2002b).

The increased expression of prostanoids present in the menorrhagic endometrium has led to the administration of COX enzyme inhibitors as a means of therapy (Stirrat, 1999). COX enzyme inhibitors such as ibuprofen reduce menstrual blood loss (Makarainen and Ylikorkala, 1986). A dual mode of action has been demonstrated for fenamates such as sodium meclofenamate and mefenamic acid which reduce prostaglandin synthesis and inhibit binding of $\mathrm{PGE}_{2}$ to its receptor (Rees et al., 1988).

\section{Dysmenorrhoea}

Primary dysmenorrhoea is a frequent occurrence in ovulating women and is often preceded by premenstrual tension and intense painful menstrual cramps occurring in the absence of a pelvic abnormality (Rees, 1989; Rees and Turnbull, 1989). Secondary dysmenorrhoea is clearly differentiated from primary dysmenorrhoea, because it is a symptom of uterine abnormalities or adnexal diseases such as endometriosis, pelvic inflammatory disease, or submucous leiomyomas (Rees, 1989; Rees and Turnbull, 1989). Primary dysmenorrhoea is associated with spastic uterine hypercontractility. During contractions, endometrial blood flow decreases and there is now good correlation between minimal blood flow and maximal pain, indicating that ischaemia due to hypercontractility is the primary cause (Rees, 1989; Rees and Turnbull, 1989). In addition, $\mathrm{PGE}_{2}$ and $\mathrm{PGF}_{2 \alpha}$ concentrations are higher in the menstrual fluid of women with dysmenorrhoea than in women with painless periods (Rees et al., 1984b; Rees, 1989). Studies in vitro have demonstrated that endometrial explants from women with dysmenorrhoea produce more $\mathrm{PGF}_{2 \alpha}$ in response to arachidonic acid compared with endometrium from pain-free women (Lundstrom and Green, 1978). This finding has prompted the use of COX enzyme inhibitors such as mefenamic acid, ibuprofen and naproxen as therapeutic regimens for management of this disorder; treatment being administered during menstruation, or before the onset of menses (Rees, 1989). More recently selective COX-2 inhibitors have proven to be even more efficacious in treatment of dysmenorrhoea and the pain associated with it (Daniels et al., 2002), making it a potential choice for treatment of women with primary dysmenorrhoea.

\section{Endometriosis}

Endometriosis is a chronic disease of unknown aetiology manifested by pelvic pain, infertility and abnormal uterine bleeding. Endometriosis is defined as the presence of endometrial glands and stroma within the pelvic peritoneum and other extra-uterine sites. Surgical findings in patients with endometriosis range from microscopic disease to frozen pelvis with extensive pelvic adhesions, complete cul-de-sac obliteration and large ovarian endometriomas (Canis et al., 1993). Sampson's (1927) theory of transplantation of endometrial tissue on the pelvic peritoneum via retrograde menstruation is one of the most widely recognized explanations for the development of pelvic endometriosis. Retrograde menstruation is observed in nearly all cyclic women, and endometriosis is considered to develop as a result of the coexistence of a defect in clearance of the menstrual efflux from the pelvic peritoneal surfaces (Halme et al., 1988).

Endometriosis is an oestrogen-dependent disorder and immunohistochemical studies have localized oestrogen receptor expression and increased expression of aromatase in epithelial and stromal cells of endometriotic tissues and peritoneum (Matsuzaki et al., 2001; Bulun et al., 2002b). Other factors including aberrant expression of cytokines, matrix metalloproteinases (MMPs) and reduction in progesterone concentrations are contributing factors important in the pathophysiology of the disease (Bulun et al., 2000a). Aromatase activity is absent in normal endometrium, but high in patients with endometriosis giving rise to local biosynthesis of oestrogen. Oestrogen promotes $\mathrm{PGE}_{2}$ synthesis, establishing a positive feedback loop to induce transcription of COX-2, synthesis of $\mathrm{PGE}_{2}$ and expression of aromatase (Bulun et al., 2000b, 2002a,b). This positive feedback cycle is partially mediated by CAMP after ligand binding to the CAMP-linked EP receptors and induction of COX-2 and favours accumulation of oestrogen and synthesis of prostaglandins to potentiate inflammation 
(Bulun et al., 2000b, 2002a,b). Immunohistochemical studies have shown that COX-2 expression is upregulated in endometriotic endometrium (Ota et al., 2001). Moreover, increased prostaglandin concentrations have been reported in the peritoneal fluid of infertile women with endometriosis, indicating that ectopic endometrium directly synthesizes and releases prostanoids into the peritoneal fluid, which could have an adverse impact on tubal function and spermatozoa, oocyte and embryo transport, thereby reducing the likelihood of conception (Haney, 1993). In addition, prostanoids in peritoneal fluid may act in a paracrine manner on surrounding tissues to sustain the state of endometriosis or facilitate further reproductive tract dysfunction. A large number of agents, many of which suppress endometriosis by oestrogen deprivation, have been used as potential therapy for suppression of endometriosis (Haney, 1993). However, endometriosis returns in $75 \%$ of these women, probably as a result of the production and release of oestradiols in adipose tissue, skin and endometriotic implant (Bulun et al., 2002b). Preliminary evidence indicates that aromatase inhibitors may be useful in treatment of endometriosis (Bulun et al., 2002b). The observation of increased COX enzyme expression and prostanoid biosynthesis in endometriotic tissue also indicates that treatment with COX enzyme inhibitors may be of therapeutic benefit in treatment of women with endometriosis.

\section{Potential cellular mechanisms for COX enzymes and prostaglandins in regulation of endometrial dysfunction}

In the previous section, evidence was provided that supported a role for COX enzymes and prostaglandins in uterine disorders. Although the underlying biochemistry is still somewhat unclear, studies using in vitro model systems have shown that enhanced synthesis of $\mathrm{PGE}_{2}$ resulting from upregulated COX enzyme expression plays a role in promoting angiogenesis (Tsujii et al., 1998), inhibiting apoptosis and enhancing proliferation (Tsujii and DuBois, 1995), increasing the metastatic potential of epithelial cells (Tsujii et al., 1997) and immunosuppression by inhibiting T-cell and B-cell proliferation and differentiation and accessory monocyte-macrophage function (DeWitt, 1991). This section outlines some of the cellular mechanisms whereby COX enzymes and prostaglandins may mediate their role in uterine pathophysiology.

\section{Angiogenesis}

COX enzymes, $\mathrm{PGE}_{2}$ and $\mathrm{EP}$ receptors regulate vascular remodelling by promoting angiogenesis. In epithelial cell lines stably transfected with COX-1 or COX-2, overexpression of COX-1 or COX-2, or both, results in a concomitant increase in the production of $\mathrm{PGE}_{2}$, and the $\mathrm{PGE}_{2}$ produced acts in an autocrine-paracrine manner on EP receptors to trigger intracellular signal transduction cascades and transcription of pro-angiogenic factors such as VEGFs, angiopoietin-1 and angiopoietin-2 (Tsujii et al., 1998; Sales et al., 2002a). These factors in turn stimulate angiogenesis by acting on endothelial cells to cause vessel sprouting and tubular structure formation (Tsujii et al., 1998; Sales et al., 2002a). Specific receptors have also been associated with the role of $\mathrm{PGE}_{2}$ in blood vessel formation. In uterine carcinomas, increased COX enzyme expression and $\mathrm{PGE}_{2}$ biosynthesis is associated with increased EP2 and EP4 receptor expression in neoplastic epithelial and endothelial cells (Jabbour et al., 2001). In knockout mouse models, ablation of the EP2 receptor is associated with a decrease in the size of intestinal polyps coincident with a decrease in angiogenic factor expression (Sonoshita et al., 2001). Similarly, COX-2, EP2 and angiogenic factor expression correlate strongly with an increase in microvessel density in other carcinomas, such as those of the colon (Seno et al., 2002). Therefore, an increased ligand-receptor interaction as a consequence of an increase in the COX-PG biosynthetic pathway (Jabbour et al., 2001; Sales et al., 2001, 2002a) can promote vascular function by enhancing the transcription of target genes involved in angiogenesis. This mechanism whereby the vasculature is regulated or dysregulated may be common for a host of endometrial disorders, and may be further regulated by the steroid hormones. Another mechanism whereby COX enzymes can regulate angiogenesis is via suppression of production of anti-angiogenic factors. Data generated in the authors' laboratory using endometrial epithelial cells over-expressing COX-2 demonstrate that COX-2 can suppress the production of anti-angiogenic factors such as angiostatin (Perchick and Jabbour, in press).

\section{Apoptosis and proliferation}

In various model systems of epithelial cell lines that overexpress COX- 1 or COX-2, a role for COX enzymes in cell proliferation and inhibition of apoptosis in response to growth factor, mitogen and cytokine stimuli has been ascertained. Selective inhibition of COX-2 in these model systems results in a decrease in cell proliferation and restoration of the apoptotic rate (Erickson et al., 1999). Epithelial cell lines stably transfected to overexpress COX-2 exhibit a higher proliferation rate and an inhibition of apoptosis by prolongation of the $\mathrm{G} 1$ phase of the cell cycle through effects on cyclin D. Administration of selective COX-2 inhibitors to these cells results in a reduction in proliferative potential and an increase in the apoptotic rate (Tsujii and DuBois, 1995; DuBois et al., 1996). These effects have also been observed in vivo after administration of COX-2 inhibitors to rats with chemically induced colon cancers, in which an increase in the apoptotic rate coincides with administration of 
selective COX-2 inhibitors (Samaha et al., 1997). In reproductive tract carcinomas, similar mechanisms may regulate tumorigenesis, as overexpression of COX-2 in cervical tumours correlates also with a reduction in apoptosis at the site of tumour invasion (Ryu et al., 2000). $\mathrm{PGE}_{2}$ and $\mathrm{PGF}_{2 \alpha}$ have been shown to directly enhance the proliferation rate of glandular epithelial cells (Milne and Jabbour, 2003), indicating a role for COX enzyme products in pathologies of the uterus that are associated with proliferation and apoptosis, such as endometriosis and cancer.

\section{Tissue invasion and metastasis}

A number of endometrial pathologies, such as endometriosis and cancer, involve local invasion of surrounding tissues. This invasion is accomplished via the degradation of the extracellular matrix by matrix metalloproteinases (MMPs). A correlation between COX-2 and MMP expression and invasiveness has been established by the observation that overexpression of COX-2 in epithelial cells upregulates production of $\mathrm{PGE}_{2}$ and expression of MMP-2. The overexpression of COX-2 in these cells promoted the invasion of surrounding matrix in in vitro model systems, which was reversed by cotreatment with COX-2 inhibitors. These data indicate that COX enzymes and prostaglandins can promote invasion of surrounding tissues and may be important in diseases such as endometriosis (Tsujii et al., 1997).

In order for cells to become mobile to invade distant parts of the body where space and nutrients are not limiting, changes in cell-surface adhesion molecules (CAMs) are needed. The most widely observed alteration in CAMs is that involving E-cadherin (Aplin et al., 1998). Model systems overexpressing E-cadherin have demonstrated a reduction in cell invasiveness and metastasis (Christofori and Semb, 1999). A link between COX enzymes and loss of cell surface adhesion molecules has been identified: COX-2 overexpressing cell lines downregulate $\mathrm{E}$-cadherin coincident with increased $\mathrm{PGE}_{2}$ production compared with wild-type and COX-2 antisense cell lines (Tsujii and DuBois, 1995). In addition, expression of E-cadherin is downregulated in a number of solid tumours and is closely and inversely related to enhanced invasion of neoplastically transformed cells (Mayer et al., 1993). Thus, COX-2 upregulation promotes cell invasion and metastases by downregulating cell adhesion molecules (Tsujii and DuBois, 1995). Whether COX-2 overexpression induces similar cellular mechanisms in solid uterine and cervical tumours and endometriosis remains to be established.

\section{Immunosuppression}

Several uterine pathologies, such as endometriosis and cancer, may also be regulated by mechanisms that allow them to bypass normal immune function. For example, the high concentrations of $\mathrm{PGE}_{2}$ present in uterine carcinomas and endometriotic tissues may inhibit B- and Tcell proliferation and accessory monocyte-macrophage function, thereby allowing defective cells to proliferate undetected by the immune system (DeWitt, 1991). Cytokines such as IL-1 are known to induce COX-2 expression in vitro (Huang et al., 1998), and may act in a similar way in situ when secreted from immune cells and macrophages in endometriotic or neoplastic uterine tissues (Halme et al., 1988). This mechanism could augment COX-2 expression and $\mathrm{PGE}_{2}$ biosynthesis and sustain immune evasion. Furthermore, in sexually active women with neoplastic utero-cervical lesion, the immunosuppressive effects of seminal plasma may further enhance any effect derived by exposure of uterinecervical cells to endogenous $\mathrm{PGE}_{2}$ (Kelly, 1995).

\section{Conclusion}

This review has highlighted several aspects of the COXPG biosynthetic pathway and its function in endometrial dysfunction and pathology. It is now clear that both COX enzymes may contribute to pathophysiology by upregulating cellular machinery involved in signal transduction and gene transcription. This finding poses a dilemma for the use of selective COX inhibitors, as these may be only of partial therapeutic benefit in reproductive tract pathologies in which both COX isoforms are upregulated. In light of the evidence for a role of the EP receptors in regulating reproductive dysfunction, the use of selective receptor antagonists and modulators of signal transduction may be more effective therapeutic regimens for treatment of reproductive tract dysfunction. These regimens would selectively block transcription of target genes involved in vascular growth, cell adhesion, proliferation and survival. This is of particular relevance and importance for sexually active women in whom the potential regulation of uterine-cervical cell function by seminal plasma must be taken into account.

\section{References}

Key references are identified by asterisks.

Adelantado JM, Lopez Bernal A and Turnbull AC (1988a) Topographical distribution of prostaglandin E receptors in human myometrium British Journal of Obstetrics and Gynaecology 95 348-353

Adelantado JM, Rees MC, Lopez Bernal A and Turnbull AC (1988b) Increased uterine prostaglandin $\mathrm{E}$ receptors in menorrhagic women British Journal of Obstetrics and Gynaecology 95 162-165

Aplin AE, Howe A, Alahari SK and Juliano RL (1998) Signal transduction and signal modulation by cell adhesion receptors the role of integrins, cadherins, immunoglobulin-cell adhesion molecules, and selectins Pharmacology Reviews 50 197-263

Ashby B (1998) Co-expression of prostaglandin receptors with opposite effects: a model for homeostatic control of autocrine and paracrine signaling Biochemical Pharmacology 55 239-246

*Bhattacharya M, Peri KG, Almazan G, Ribeiro-da-Silva A, Shichi H, Durocher Y, Abramovitz M, Hou X, Varma DR and Chemtob S (1998) Nuclear localization of prostaglandin E2 receptors Proceedings National Academy of Sciences USA $9515792-15797$ 
*Bhattacharya M, Peri K, Ribeiro-da-Silva A, Almazan G, Shichi H, Hou X, Varma DR and Chemtob S (1999) Localization of functional prostaglandin E2 receptors EP3 and EP4 in the nuclear envelope Journal of Biological Chemistry 27415 719-15 724

Bulun SE, Zeitoun KM, Takayama K and Sasano H (2000a) Estrogen biosynthesis in endometriosis molecular basis and clinical relevance Journal of Molecular Endocrinology 25 35-42

Bulun SE, Zeitoun KM, Takayama K and Sasano H (2000b) Molecular basis for treating endometriosis with aromatase inhibitors Human Reproduction Update 6 413-418

Bulun SE, Gurates B, Fang Z, Tamura M, Sebastian S, Zhou J, Amin S and Yang S (2002a) Mechanisms of excessive estrogen formation in endometriosis Journal of Reproductive Immunology 55 21-33

Bulun SE, Yang S, Fang Z, Gurates B, Tamura M and Sebastian S (2002b) Estrogen production and metabolism in endometriosis Annals of the New York Academy of Science 955 75-85

Buttram VC, Jr and Reiter RC (1981) Uterine leiomyomata etiology, symptomatology, and management Fertility and Sterility 36 433-445

Canis M, Bouquet De Jolinieres J, Wattiez A, Pouly JL, Mage G, Manhes H and Bruhat MA (1993) Classification of endometriosis Bailliere's Clinical Obstetrics and Gynaecology 7 759-774

Chan BS, Satriano JA, Pucci M and Schuster VL (1998) Mechanism of prostaglandin E2 transport across the plasma membrane of HeLa cells and Xenopus oocytes expressing the prostaglandin transporter 'PGT' Journal of Biological Chemistry 273 6689-6697

*Chandrasekharan NV, Dai H, Roos KL, Evanson NK, Tomsik J, Elton TS and Simmons DL (2002) COX-3, a cyclooxygenase-1 variant inhibited by acetaminophen and other analgesic/antipyretic drugs: cloning, structure, and expression Proceedings National Academy of Sciences USA 99 13 926-13931

Chiarugi V, Magnelli L and Gallo O (1998) Cox-2, iNOS and p53 as play-makers of tumor angiogenesis International Journal of Molecular Medicine 2 715-719

Christofori G and Semb H (1999) The role of the cell-adhesion molecule E-cadherin as a tumour- suppressor gene Trends in Biochemical Sciences 24 73-76

Chulada PC, Thompson MB, Mahler JF, Doyle CM, Gaul BW, Lee C, Tiano HF, Morham SG, Smithies O and Langenbach R (2000) Genetic disruption of Ptgs-1, as well as Ptgs-2, reduces intestinal tumorigenesis in Min mice Cancer Research 60 4705-4708

Clancy R, Varenika B, Huang W, Ballou L, Attur M, Amin AR and Abramson SB (2000) Nitric oxide synthase/COX cross-talk nitric oxide activates COX-1 but inhibits COX-2-derived prostaglandin production Journal of Immunology 165 1582-1587

Coleman RA, Smith WL and Narumiya S (1994) International Union of Pharmacology classification of prostanoid receptors properties, distribution, and structure of the receptors and their subtypes Pharmacology Reviews 46 205-229

Daniels SE, Talwalker S, Torri S, Snabes MC, Recker DP and Verburg KM (2002) Valdecoxib, a cyclooxygenase-2-specific inhibitor, is effective in treating primary dysmenorrhea Obstetrics and Gynecology 100350 358

DeWitt DL (1991) Prostaglandin endoperoxide synthase regulation of enzyme expression Biochimica et Biophysica Acta 1083 121-134

Dinchuk JE, Car BD, Focht RJ, Johnston JJ, Jaffee BD, Covington MB, Contel NR, Eng VM, Collins RJ, Czerniak PM and et al (1995) Renal abnormalities and an altered inflammatory response in mice lacking cyclooxygenase II Nature 378 406-409

DuBois RN, Shao J, Tsujii M, Sheng H and Beauchamp RD (1996) G1 delay in cells overexpressing prostaglandin endoperoxide synthase-2 Cancer Research $\mathbf{5 6} 733-737$

Erickson BA, Longo WE, Panesar N, Mazuski JE and Kaminski DL (1999) The effect of selective cyclooxygenase inhibitors on intestinal epithelial cell mitogenesis Journal of Surgery Research 81 101-107

Ferrandina G, Legge F, Ranelletti FO, Zannoni GF, Maggiano N, Evangelisti A, Mancuso S, Scambia G and Lauriola L (2002) Cyclooxygenase-2 expression in endometrial carcinoma correlation with clinicopathologic parameters and clinical outcome Cancer 95 801-807
Forman BM, Chen J and Evans RM (1997) Hypolipidemic drugs, polyunsaturated fatty acids, and eicosanoids are ligands for peroxisome proliferator-activated receptors alpha and delta Proceedings National Academy of Sciences USA 94 4312-4317

Fraser IS (1992) Prostaglandins, prostaglandin inhibitors and their roles in gynaecological disorders Bailliere's Clinical Obstetrics and Gynaeco$\log 6$ 829-857

Fujino H, Srinivasan D and Regan JW (2002) Cellular conditioning and activation of beta-catenin signalling by the FPB prostanoid receptor Journal of Biological Chemistry $27748786-48795$

Gross GA, Imamura T, Luedke C, Vogt SK, Olson LM, Nelson DM, Sadovsky Y and Muglia LJ (1998) Opposing actions of prostaglandins and oxytocin determine the onset of murine labor Proceedings National Academy of Sciences USA $9511875-11879$

Halme J, White C, Kauma S, Estes J and Haskill S (1988) Peritoneal macrophages from patients with endometriosis release growth factor activity in vitro. Journal of Clinical Endocrinology and Metabolism 66 1044-1049

Haney AF (1993) Endometriosis-associated infertility Bailliere's Clinical Obstetrics and Gynaecology 7 791-812

Haynes PJ, Hodgson H, Anderson AB and Turnbull AC (1977) Measurement of menstrual blood loss in patients complaining of menorrhagia British Journal of Obstetrics and Gynaecology 84763 768

Hizaki H, Segi E, Sugimoto $Y$, Hirose M, Saji T, Ushikubi F, Matsuoka T, Noda Y, Tanaka T, Yoshida N, Narumiya S and Ichikawa A (1999) Abortive expansion of the cumulus and impaired fertility in mice lacking the prostaglandin E receptor subtype EP(2) Proceedings National Academy of Sciences USA 9610 501-10 506

Hofmann GE, Rao CV, Barrows GH and Sanfilippo JS (1983) Topography of human uterine prostaglandin E and F2 alpha receptors and their profiles during pathological states Journal of Clinical Endocrinology and Metabolism 57 360-366

Huang JC, Liu DY, Yadollahi S, Wu KK and Dawood MY (1998) Interleukin-1 beta induces cyclooxygenase-2 gene expression in cultured endometrial stromal cells Journal of Clinical Endocrinology and Metabolism 83538 541

Jabbour HN, Milne SA, Williams ARW, Anderson RA and Boddy SC (2001) Expression of COX-2 and PGE synthase and synthesis of PGE2 in endometrial adenocarcinoma a possible autocrine/paracrine regulation of neoplastic cell function via EP2/EP4 receptors British Journal of Cancer 85 1023-1031

Kelly RW (1995) Immunosuppressive mechanisms in semen implications for contraception Human Reproduction 10 1686-1693

Kennedy CR, Zhang Y, Brandon S, Guan Y, Coffee K, Funk CD, Magnuson MA, Oates JA, Breyer MD and Breyer RM (1999) Salt-sensitive hypertension and reduced fertility in mice lacking the prostaglandin EP2 receptor Nature Medicine 5 217-220

Kulkarni S, Rader JS, Zhang F, Liapis H, Koki AT, Masferrer JL, Subbaramaiah K and Dannenberg AJ (2001) Cyclooxygenase-2 is overexpressed in human cervical cancer Clinical Cancer Research 7 429-434

Langenbach R, Morham SG, Tiano HF et al. (1995) Prostaglandin synthase 1 gene disruption in mice reduces arachidonic acid-induced inflammation and indomethacin-induced gastric ulceration Cell 83 483-492

*Langenbach R, Loftin C, Lee C and Tiano H (1999a) Cyclooxygenase knockout mice models for elucidating isoform-specific functions Biochemical Pharmacology 58 1237-1246

Langenbach R, Loftin CD, Lee C and Tiano H (1999b) Cyclooxygenasedeficient mice: a summary of their characteristics and susceptibilities to inflammation and carcinogenesis Annals of the New York Academy of Sciences 889 52-61

*Lim H, Paria BC, Das SK, Dinchuk JE, Langenbach R, Trzaskos JM and Dey SK (1997) Multiple female reproductive failures in cyclooxygenase 2-deficient mice Cell 91 197-208

Lundstrom V and Green K (1978) Endogenous levels of prostaglandin F2alpha and its main metabolites in plasma and endometrium of normal and dysmenorrheic women American Journal of Obstetrics and Gynecology 130 640-646 
Makarainen L and Ylikorkala O (1986) Primary and myoma-associated menorrhagia role of prostaglandins and effects of ibuprofen British Journal of Obstetrics and Gynaecology 93 974-978

Maldve RE, Kim Y, Muga SJ and Fischer SM (2000) Prostaglandin E(2) regulation of cyclooxygenase expression in keratinocytes is mediated via cyclic nucleotide-linked prostaglandin receptors Journal of Lipid Research 41 873-881

Marnett LJ (1992) Aspirin and the potential role of prostaglandins in colon cancer Cancer Research 52 5575-5589

Matsuzaki S, Murakami T, Uehara S, Canis M, Sasano H and Okamura K (2001) Expression of estrogen receptor alpha and beta in peritoneal and ovarian endometriosis Fertility and Sterility $\mathbf{7 5}$ 1198-1205

Mayer B, Johnson JP, Leitl F, Jauch KW, Heiss MM, Schildberg FW, Birchmeier W and Funke I (1993) E-cadherin expression in primary and metastatic gastric cancer down regulation correlates with cellular dedifferentiation and glandular disintegration Cancer Research $\mathbf{5 3}$ 1690-1695

Milne SA and Jabbour HN (2003) Prostaglandin (PG) F(2alpha) receptor expression and signaling in human endometrium role of PGF(2alpha) in epithelial cell proliferation Journal of Clinical Endocrinology and Metabolism 88 1825-1832

Morita I (2002) Distinct functions of COX-1 and COX-2 Prostaglandins and Other Lipid Mediators 68-69 165-175

Narumiya S and FitzGerald GA (2001) Genetic and pharmacological analysis of prostanoid receptor function Journal of Clinical Investigation $10825-30$

Narumiya S, Sugimoto Y and Ushikubi F (1999) Prostanoid receptors structures, properties, and functions Physiology Reviews 79 1193-1226

Ota H, Igarashi S, Sasaki M and Tanaka T (2001) Distribution of cyclooxygenase-2 in eutopic and ectopic endometrium in endometriosis and adenomyosis Human Reproduction 16 561-566

Perchick GB and Jabbour HN COX-2 overexpression inhibits cathepsin Dmediated cleavage of plasminogen to the potent anti-angiogenic factor angiostatin Endocrinology (in press)

Prentice A (2000) Health burden of menstrual disorders. In Disorders of the Menstrual Cycle pp 13-23 Eds S O'Brien et al. ACOG Press, London

Rees MC (1989) Heavy, painful periods Bailliere's Clinical Obstetrics and Gynaecology 3 341-356

Rees MC and Turnbull AC (1989) Menstrual disorders - an overview Bailliere's Clinical Obstetrics and Gynaecology 3 217-226

Rees MC, Anderson AB, Demers LM and Turnbull AC (1984a) Endometrial and myometrial prostaglandin release during the menstrual cycle in relation to menstrual blood loss Journal of Clinical Endocrinology and Metabolism 58 813-818

Rees MC, Demers LM, Anderson AB and Turnbull AC (1984b) A functional study of platelets in menstrual fluid British Journal of Obstetrics and Gynaecology 91 667-672

Rees MC, Canete-Soler R, Lopez Bernal A and Turnbull AC (1988) Effect of fenamates on prostaglandin E receptor binding Lancet 2 541-542

Ryu HS, Chang KH, Yang HW, Kim MS, Kwon HC and Oh KS (2000) High cyclooxygenase-2 expression in stage IB cervical cancer with lymph node metastasis or parametrial invasion Gynecologic Oncology $\mathbf{7 6}$ 320-325

Sales KJ, Katz AA, Davis M, Hinz S, Soeters RP, Hofmeyr MD, Millar RP and Jabbour HN (2001) Cyclooxygenase-2 expression and prostaglandin $E(2)$ synthesis are upregulated in carcinomas of the cervix a possible autocrine/paracrine regulation of neoplastic cell function via EP2/EP4 receptors Journal of Clinical Endocrinology and Metabolism 86 22432249

*Sales KJ, Katz AA, Howard B, Soeters RP, Millar RP and Jabbour HN (2002a) Cyclooxygenase-1 is upregulated in cervical carcinomas autocrine/paracrine regulation of cyclooxygenase-2, PGE receptors and angiogenic factors by cyclooxygenase-1 Cancer Research 62 424432

Sales KJ, Katz AA, Millar RP and Jabbour HN (2002b) Seminal plasma activates cyclooxygenase-2 and prostaglandin $\mathrm{E}(2)$ receptor expression and signalling in cervical adenocarcinoma cells Molecular Human Reproduction 8 1065-1070

Samaha HS, Kelloff GJ, Steele V, Rao CV and Reddy BS (1997) Modulation of apoptosis by sulindac, curcumin, phenylethyl-3-methylcaffeate and 6-phenylhexyl isothyocyanate apoptotic index as a biomarker in colon cancer chemoprevention and promotion Cancer Research 57 13011305

Sampson JA (1927) Peritoneal endometriosis due to the menstrual dissemination of endometrial tissue into the peritoneal cavity American Journal of Obstetrics and Gynaecology 14 422-425

Seno H, Oshima M, Ishikawa T, Oshima H, Takaku K, Chiba T, Narumiya S and Taketo MM (2002) Cyclooxygenase-2 and prostaglandin E2 receptor EP2-dependent angiogenesis in APC delta 716 mouse intestinal polyps Cancer Research 62 506-511

Sheng H, Shao J, Washington MK and DuBois RN (2001) Prostaglandin E2 increases growth and motility of colorectal carcinoma cells Journal of Biological Chemistry 27618 075-18081

Smith SK, Abel MH, Kelly RW and Baird DT (1981a) Prostaglandin synthesis in the endometrium of women with ovular dysfunctional uterine bleeding British Journal of Obstetrics and Gynaecology $\mathbf{8 8}$ 434-442

Smith SK, Abel MH, Kelly RW and Baird DT (1981b) A role for prostacyclin (PGi2) in excessive menstrual bleeding Lancet 1 522-524

Sonoshita M, Takaku K, Sasaki N, Sugimoto Y, Ushikubi F, Narumiya S, Oshima M and Taketo MM (2001) Acceleration of intestinal polyposis through prostaglandin receptor EP2 in APC delta 714 knockout mice Nature Medicine 7 1048-1051

Stirrat GM (1999) Choice of treatment for menorrhagia Lancet 3532175 2176

Subbaramaiah K, Zakim D, Weksler BB and Dannenberg AJ (1997) Inhibition of cyclooxygenase: a novel approach to cancer prevention Proceedings of the Society for Experimental Biology and Medicine 216 201-210

Sugimoto Y, Negishi M, Hayashi Y, Namba T, Honda A, Watabe A, Hirata M, Narumiya S and Ichikawa A (1993) Two isoforms of the EP3 receptor with different carboxyl-terminal domains: identical ligand binding properties and different coupling properties with Gi proteins Journal of Biological Chemistry 268 2712-2718

Sugimoto Y, Segi E, Tsuboi K, Ichikawa A and Narumiya S (1998) Female reproduction in mice lacking the prostaglandin $\mathrm{F}$ receptor. Roles of prostaglandin and oxytocin receptors in parturition Advances in Experimental Medicine and Biology 449 317-321

Tilley SL, Audoly LP, Hicks EH, Kim HS, Flannery PJ, Coffman TM and Koller BH (1999) Reproductive failure and reduced blood pressure in mice lacking the EP2 prostaglandin E2 receptor Journal of Clinical Investigation 103 1539-1545

Tong BJ, Tan J, Tajeda L, Das SK, Chapman JA, DuBois RN and Dey SK (2000) Heightened expression of cyclooxygenase-2 and peroxisome proliferator-activated receptor- $\delta$ in human endometrial adenocarcinoma Neoplasia 2 483-490

*Tsujii M and DuBois RN (1995) Alterations in cellular adhesion and apoptosis in epithelial cells overexpressing prostaglandin endoperoxide synthase 2 Cell 83 493-501

*Tsujii M, Kawano S and DuBois RN (1997) Cyclooxygenase-2 expression in human colon cancer cells increases metastatic potential Proceedings National Academy of Sciences USA 94 3336-3340

*Tsujii M, Kawano S, Tsuji S, Sawaoka H, Hori M and DuBois RN (1998) Cyclooxygenase regulates angiogenesis induced by colon cancer cells Cell 93 705-716

Watanabe K, Kawamori T, Nakatsugi S et al. (1999) Role of prostaglandin E receptor subtype EP1 in colon carcinogenesis Cancer Research $\mathbf{5 9}$ 5093-5096

Watanabe K, Kawamori T, Nakatsugi S et al. (2000) Inhibitory effect of a prostaglandin E receptor subtype EP1 selective antagonist, ONO-8713, on development of azoxymethane-induced aberrant crypt foci in mice Cancer Letters 156 57-61 